\title{
NOTA
}

\section{APHANES ARVENSIS (ROSACEAE) EN EL EXTREMO NORDESTE DE LA ARGENTINA}

\author{
GUSTAVO HILDT ${ }^{1} \&$ HÉCTOR A. KELLER²
}

\begin{abstract}
Summary: Hildt, G. \& H. A. Keller. 2014. Aphanes arvensis (Rosaceae) in the extreme northeastern of Argentina. Bonplandia 23(1): 51-53.

A herb adventitious in the New World, is mentioned for the first time for the northeastern Argentina. The species is illustrated by mean photographies.
\end{abstract}

Key words: Aphanes, adventitious plants, herb, Misiones.

Resumen: Hildt, G. \& H. A. Keller. 2014. Aphanes arvensis (Rosaceae) en el extremo nordeste de la Argentina. Bonplandia 23(1): 51-53.

Se menciona por primera vez para el nordeste argentino a una hierba adventicia en el nuevo mundo. La especie es ilustrada mediante fotografías.

Palabras clave: Aphanes, plantas adventicias, hierba, Misiones.

\section{Introducción}

El género Aphanes L. está representado por hierbas anuales, cuyas flores apétalas poseen cáliz con 4(5) lóbulos que alternan con 4(5) bractéolas del calículo, y cuentan sólo con 1-3 estambres fértiles; caracteres que permiten separarlo de otros géneros de la familia Rosaceae (Linnaeus, 1753; Reitz, 1996). Dos especies han sido documentadas para nuestro país; Aphanes parodii (I. M. Johnst.) Rothm., es una especie nativa, hasta el presente recolectada en Buenos Aires, Chubut, Córdoba, Distrito Federal, La Pampa, Santa Cruz y Santa Fe. Aphanes arvensis L. ha sido documentada como especie adventicia en las provincias de Río Negro y Neuquén (Grondona, 1984). Sobre la base de ejemplares de herbario recientemente recolectados en la localidad de Bernardo de Irigoyen, Depto. Gral. Manuel Belgrano, Misiones, Argentina, la presente contribución tiene como objetivo notificar la presencia de esta última especie en el nordeste argentino.

El hallazgo permite ampliar a cinco los géneros de la familia Rosaceae con especies adventicias en la provincia de Misiones: Aphanes L. (esta contribución); Agrimonia L. (Zardini, 1999); Eriobotrya Lindl. (Delucchi \& Keller, 2010); Prunus L. (Delucchi, 2011) y Rubus L. (Marticorena, 2008).

\footnotetext{
${ }^{1}$ Facultad de Ciencias Forestales, Universidad Nacional de Misiones. Bertoni 124, (3380), Eldorado, Misiones.

${ }^{2}$ Instituto de Botánica del Nordeste (CONICET-UNNE), Casilla de Correo 209, (3400), Corrientes, Argentina. E-mail: hakeller2000@yahoo.com.ar
} 
Aphanes arvensis L. Sp. P1. 123. 1753 (Fig. 1).

Alchemilla arvensis (L.) Scop., Fl. Carniol. ed. 2, 1: 115. 1771.

Iconografía y descripción ampliada: Frost-Olsen (1997).

Hierba verde cenicienta de hasta $50 \mathrm{~cm}$ alt., con tallos decumbentes a ascendentes, ramificados y pilosos. Hojas profundamente trífidas con segmentos divididos en 3-5 lóbulos oblongos. Pecíolos cortos adnatos a las estípulas. Estípulas con 5-7 lóbulos triangulares, pilosos o ciliados. Inflorescencias más o menos sésiles, opuestas a las hojas e incluidas en las estípulas. Flores ca. $2 \mathrm{~mm}$ long., vestidas por un cáliz campanulado, pubescente, 4-lobulado. Lóbulos del cáliz erectos, ovados, agudos, alternando con 4 pequeñas bractéolas externas. Estambres 1(23). Aquenios ca. $1 \mathrm{~mm}$ long., glabros, ovados, aplanados, incluidos en el hipanto.

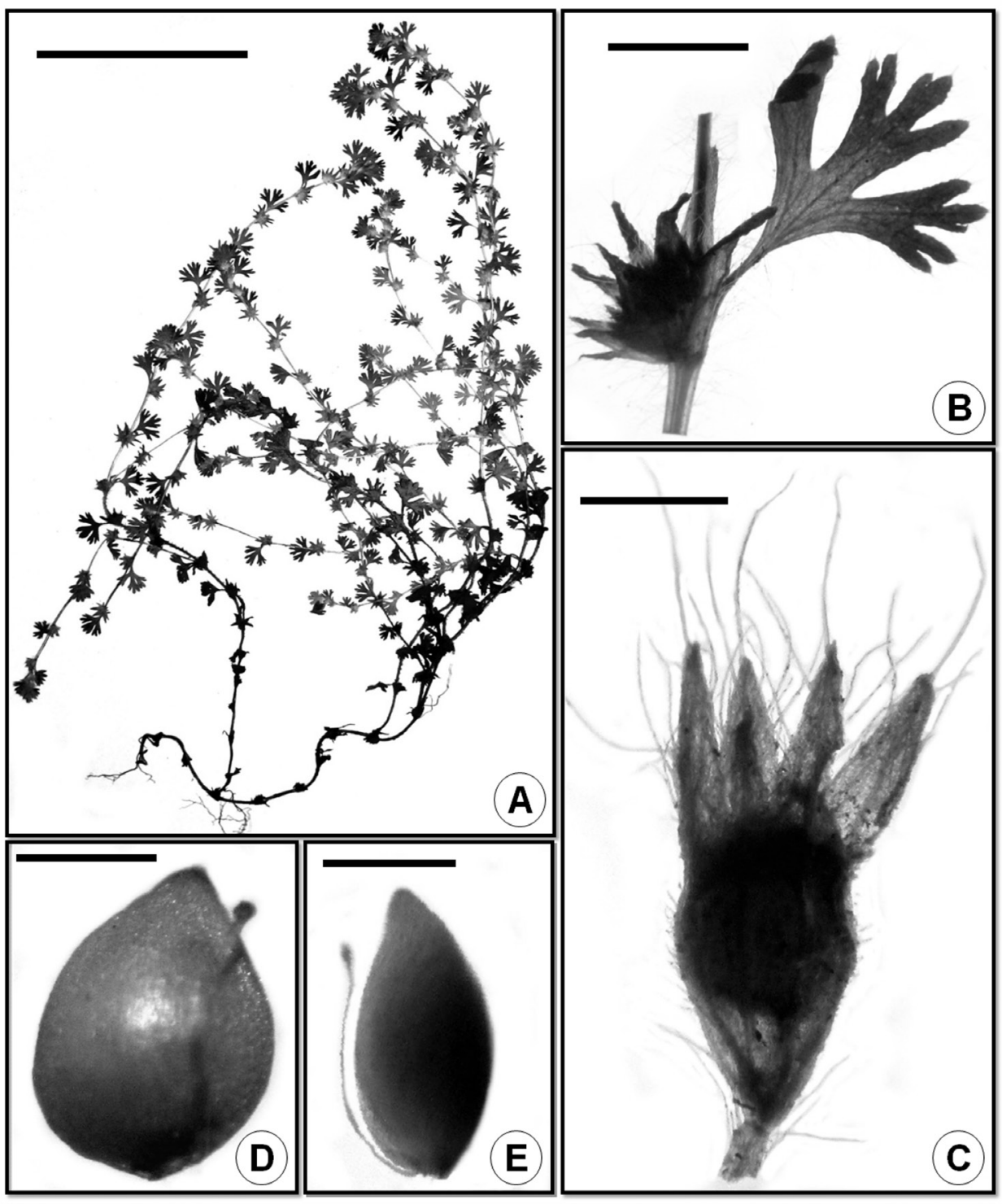

Fig. 1. Aphanes arvensis. A: Aspecto de la planta. B: Nudo florífero con hoja y estípulas. C: Fruto incluido en el hipanto. D y E: Aquenio con restos del estambre (Keller \& Hildt 11718 (CTES). Escalas en cm. A: 10; B: 0,5; C: 0,06; D y E: 0,04 . 
Material examinado: ARGENTINA. Misiones: Gral. Manuel Belgrano, Bdo. de Irigoyen, 26ำ ${ }^{\circ}$ 31,3 " S, 5340'46,5" W, 15-X-2013, fl, fr, Keller \& Hildt 11718 (CTES).

Nombres vulgares: "afanes", "rompe piedra de los ingleses” (Reitz, 1996).

Distribución geográfica: Hierba nativa del viejo mundo, de la región mediterránea hasta Escandinavia, Siberia y norte de África. Adventicia en América del Norte y Sudamérica (Brasil, Argentina y Chile). En Brasil ha sido hallada sólo en una localidad del estado de Santa Catarina, a más de $1000 \mathrm{~m}$ de altitud (Reitz, 1996) y a unos $375 \mathrm{~km}$ del sitio de hallazgo en Misiones. En la Argentina ocurre en las provincias de Misiones, Neuquén y Río Negro.

Observaciones ecológicas: Especie de reproducción apomíctica facultativa (FrostOlsen, 1997), hierba anual o bienal, heliófila y posiblemente sin acentuadas preferencias físicas especiales de suelos, encontrada como planta ruderal, preferentemente en las proximidades de las construcciones rurales, en los corrales, en los terrenos de cultivo o suelos rocosos de campos bastante pisoteados (Reitz, 1996). Ha sido mencionada como común en cultivos, barbechos, terrenos alterados, pastos terofíticos, repisas de roquedos, taludes, arenales costeros, etc.; en suelos arenosos, más o menos encharcados en invierno; rara vez en hábitats naturales (Frost-Olsen, 1997). Los ejemplares hallados en la provincia de Misiones medraban a $815 \mathrm{~m}$ de altitud, en un camino encharcado, de poco uso, en proximidades a una vivienda abandonada.

\section{Bibliografía}

DELUCCHI, G. 2011. Sinopsis de las especies de Rosaceae adventicias: subfamilia Prunoideae. Bonplandia 20: 73-94.

\& H. A. KELLER. 2010. La naturalización del "níspero", Eriobotrya japonica (Thunb.) Lindl. (Rosaceae, Maloideae) en la Argentina. Bonplandia 19: 71-77.

FROST-OLSEN, P. 1997. Aphanes L. En Castroviejo, S., Aedo, C., Laínz, M., Muñoz Garmendia, F., Nieto Feliner, G., Paiva, J. \& Benedí, C. (eds.). Flora Ibérica 6: 357-369. Real Jardín Botánico, CSIC.

GRONDONA, E. M. 1984. Rosaceae. En M. N. Correa (ed.), Fl. Patagónica, Colecc. Ci. Inst. Nac. Tecnol. Agropecu. 8(4b): 48-88.

MARTICORENA, A. 2008. Rosaceae. En: F. O. Zuloaga, O. Morrone \& M. J. Belgrano (eds.), Catálogo de las Plantas Vasculares del Cono Sur (Argentina, sur de Brasil, Chile, Paraguay y Uruguay). Monogr. Syst. Bot. Missouri Bot. Gard. 107: 2852-2871.

REITZ, P. R. 1996. Rosáceas, en A. Reis (ed.). Fl. Il. Catarinense ROSA: 5-135.

ZARDINI, E. M. 1999. Rosaceae. En Zuloaga, F. O. \& O. Morrone (eds.), Catálogo de las Plantas Vasculares de la República Argentina. II. Angiospermae (Dicotyledoneae). Monogr. Syst. Bot. Missouri Bot. Gard. 74: 1-1269. 
